\title{
GEP associates with wild-type p53 in hepatocellular carcinoma
}

\author{
SIU TIM CHEUNG* ${ }^{*}$ SAN YU WONG* ${ }^{*}$ YUK TING LEE and SHEUNG TAT FAN \\ Centre for the Study of Liver Disease and Department of Surgery, University of Hong Kong, Pokfulam, Hong Kong, China
}

Received November 4, 2005; Accepted December 29, 2005

\begin{abstract}
Granulin-epithelin precursor (GEP) is a novel growth factor whose up-regulation we previously reported in $72 \%$ of hepatocellular carcinoma (HCC). GEP expression has been reported to be associated with $\mathrm{p} 53$ protein accumulation in a breast cancer study, though the p53 mutation status was not revealed. We aim to investigate whether p53 protein and mutation status correlates with GEP expression in HCC. The statistical comparison of p53 and GEP data revealed an overall positive association between the two protein expression patterns $(\mathrm{P}<0.001)$. Upon detailed analysis, the association of p53 and GEP protein expression was found to be highly significant only in HCCs with wild-type p53 $(\mathrm{P}=0.001)$; there was no association in HCCs with p53 mutation $(\mathrm{P}=0.669)$. The GEP levels in the HepG2 hepatoma cell line with a wild-type p53 background were modulated by transfection experiments. Overexpression of the GEP protein resulted in an increased p53 protein level and suppression of the GEP protein resulted in a decreased p53 protein level in HepG2 cells. In summary, we demonstrated that p53 wild-type protein nuclei accumulation is associated with GEP protein expression in human HCC specimens, and GEP modulates p53 wild-type protein levels in vitro.
\end{abstract}

\section{Introduction}

Granulin-epithelin precursor (GEP) is a novel growth factor expressed in a number of aggressive cancers (1-11). GEP has also been reported to be involved in the wound healing process (12) and murine development (13). We have shown that GEP overexpression is common in hepatocellular

Correspondence to: Dr Siu Tim Cheung, Department of Surgery, University of Hong Kong, L9-55, Faculty of Medicine Building, 21 Sassoon Road, Hong Kong, China

E-mail: stcheung@hkucc.hku.hk

\section{${ }^{*}$ Contributed equally}

Abbreviations: GEP, granulin-epithelin precursor; HCC, hepatocellular carcinoma

Key words: granulin-epithelin precursor, progranulin, PC cellderived growth factor, acrogranin, liver cancer, p53 carcinoma (HCC) $(72 \%, 79 / 110)$, and GEP controls the cell proliferation rates and tumor invasion ability in HCC (11).

p53 is a tumor suppressor gene associated with approximately half of all human cancers worldwide (14-18). Mutation of the p53 gene results in a biologically altered protein with increased stability and nuclear accumulation $(19,20)$ and has been observed in diverse cancer types including HCC. However, p53 protein accumulation is not always dependent on p53 gene mutation, and the mechanism involved is unclear (21-25). Serrero and Ioffe have reported the association of p53 and GEP protein expression in breast cancer, although the p53 genotype was not characterized in their report (5).

The aim of the current study is to evaluate whether these two important factors, GEP and p53, have any association in HCC. We used the immunohistochemistry method to detect p53 protein nuclei accumulation and direct DNA sequencing to examine p53 gene mutations. The association of p53 and GEP protein expression was highly significant in HCCs with wild-type p53. Transfection experiments were performed to modulate the expression levels of GEP in hepatoma cells with a wild-type p53 background. Here, we report that the GEP expression level positively regulates the level of wildtype p53 protein in HCC.

\section{Patients and methods}

Patients and specimens. The study protocol was approved by the Ethics Committee of the University of Hong Kong, and informed consent was obtained from all patients. Between March 1999 and April 2000, 55 patients undergoing resection of HCC at our institute were recruited for the current study. The clinicopathological data were prospectively collected from 42 men and 13 women, and serum hepatitis B surface antigen was positive in 49 patients $(89.1 \%)$. Each HCC tissue specimen, approximately $0.5 \mathrm{~cm}^{3}$, was divided into small portions. One portion was formalin-fixed and paraffinembedded for histological and immunohistochemical studies. The other portions were snap-frozen in liquid nitrogen and stored at $-70^{\circ} \mathrm{C}$ until use. DNA was extracted using the Genomic DNA kit (Qiagen, Hilden, Germany).

Immunohistochemical staining. Immunohistochemistry was performed as described (11). For p53 detection, monoclonal antibody DO-7 (Dako, Carpinteria, CA, USA) in a 1:50 dilution was used. For GEP detection, $2 \mu \mathrm{g} / \mathrm{ml}$ of GEP antibody was used (11). Peroxidase blocking, secondary antibody and color development were performed using the Dako Envision Plus System (Dako, Carpinteria, CA, USA). 
Table I. Association of p53 mutation, p53 and granulinepithelin precursor (GEP) protein expression.

\begin{tabular}{lccc}
\hline & \multicolumn{2}{c}{ GEP expression } & \\
\cline { 2 - 2 } & Low & High & P-value \\
\hline All HCCs & & & \\
p53 protein & & & \\
$\quad$ Negative & 23 & 4 & $<0.001^{*}$ \\
$\quad$ Positive & 11 & 17 & \\
HCCs with p53 wild-type & & & \\
p53 protein & & & \\
$\quad$ Negative & 16 & 2 & $0.001^{*}$ \\
$\quad$ Positive & 3 & 8 & \\
HCCs with p53 missense mutation & & & \\
p53 protein & & & \\
$\quad$ Negative & 2 & 2 & 0.669 \\
$\quad$ Positive & 8 & 9 & \\
HCCs with p53 frameshift mutation & & & \\
p53 protein & & & \\
$\quad$ Negative & & & \\
$\quad$ Positive & 5 & 0 & ND \\
\hline
\end{tabular}

HCC, hepatocellular carcinoma; ND, not determined for a small number of samples.

Gene sequencing. Direct DNA sequencing was performed for exons 4-9 of p53, in which $>80 \%$ of all mutations were observed (14-18). Primer sets and reaction conditions were adopted from Lehman et al (26). DNA was amplified by polymerase chain reaction and direct DNA sequencing was performed with the BigDye Sequencing kit (Applied Biosystems, Foster City, CA, USA). Electrophoresis and sequence analysis were performed using the ABI PRISM 3100 (Applied Biosystems).

Transfection. The HepG2 hepatoma cell line (American Type Culture Collection, Rockville, MD, USA) containing wildtype p53 was used. The GEP cDNA encoding a full-length and antisense fragment was cloned into the mammalian expression vector pcDNA3.1 as described (11). The cells were transfected with different constructs using LipofectAmine (Invitrogen, Carlsbad, CA, USA) and plated under G418 (USB, Cleveland, OH, USA) selection.

Western blot analysis. Total protein $(20 \mu \mathrm{g})$ was separated in $10 \%$ SDS-PAGE gel and transferred to a polyvinylidene difluoride membrane (Millipore, Bedford, MA, USA). The blots were blocked with $10 \%$ non-fat dry milk, probed against GEP or p53 antibodies, followed by anti-rabbit immunoglobulin conjugated with horseradish peroxidase (Sigma-Aldrich, St. Louis, MO, USA). Control antibodies against B-actin (Santa Cruz Biotechnology, Santa Cruz, CA, USA) were used for protein loading normalization. The bands were visualized using the Enhanced Chemiluminescence Western Blotting Detection kit (Amersham Biosciences, Buckinghamshire, UK) and exposed on Hyperfilm ${ }^{\mathrm{TM}}$ (Amersham Biosciences).
Statistical analysis. Statistical analysis was carried out using statistical software (SPSS version 12.0 for Windows; SPSS, Chicago, IL, USA). The comparison of categorical variables was examined using the Chi-square test, or Fisher's exact test for a small sample size. Differences were considered statistically significant if P-value $<0.05$.

\section{Results}

p53 protein accumulation and gene mutation. $\mathrm{p} 53$ protein accumulation in the nucleus of neoplastic hepatocytes was observed in 28 of 55 (50.9\%) HCCs (Table I, Fig. 1). The mutational status of the p53 gene was then investigated for its correlation with p53 protein accumulation (Table I). Frameshift mutations were observed in 5 HCCs (one base deletion in 2 cases, small region deletion in 1 case, one base insertion in 1 case, and two base insertion in 1 case). Missense mutations were observed in $21 \mathrm{HCCs}$ (one amino acid substitution in 19 cases, and two amino acid substitutions in 2 cases). Wild-type sequences were observed in 29 HCCs. On the whole, p53 mutation was significantly associated with p53 protein accumulation (17 of 28 HCCs with p53 mutation overexpressed the 553 protein, whereas 18 of $27 \mathrm{HCCs}$ with wild-type $\mathrm{p} 53$ revealed no $\mathrm{p} 53$ protein accumulation; $\mathrm{P}=0.042$ ). The current data were comparable with earlier reports on p53 mutation and $\mathrm{p} 53$ protein accumulation.

Association of p53 and GEP in human HCC. We examined the GEP protein expression level in an earlier study (11). The GEP data were retrieved and compared with the p53 protein and gene mutation status (Table I). Overexpression of GEP in HCCs was significantly associated with $\mathrm{p} 53$ protein accumulation $(\mathrm{P}<0.001)$ (Table I). The current data derived from HCCs were comparable to a study by Serrero and Ioffe which reported that GEP overexpression is associated with p53 protein overexpression in breast cancer (13).

Further analysis based on the p53 mutation status revealed a new link between p53 and GEP (Table I). In HCCs that revealed a p53 missense mutation, the majority showed p53 protein accumulation $(81.0 \%, 17 / 21)$ and no association with GEP overexpression $(\mathrm{P}=0.669)$. In HCCs with a 553 frameshift mutation $(n=5), p 53$ protein was undetectable. Data on the association of $\mathrm{p} 53$ mutation with $\mathrm{p} 53$ protein accumulation status were concordant with the literature. Of note, in HCCs with the wild-type p53 gene, $\mathrm{p} 53$ protein accumulation was common $(37.9 \%, 11 / 29)$ and was significantly associated with strong GEP expression $(\mathrm{P}=0.001)$ (Table I). This is the first report to reveal up-regulation of growth factor GEP in association with the accumulation of wild-type p53 nuclei protein in human tumor tissue.

GEP-modulated wild-type p53 protein levels. The HepG2 hepatoma cell line with wild-type p53 was used (Fig. 2). Increased GEP protein levels by transfection of a full-length GEP expression construct resulted in increased p53 protein levels. Similarly, decreased GEP protein levels by transfection of an anti-sense GEP fragment construct resulted in decreased p53 protein levels in HepG2 with wild-type p53. These data indicated that GEP can modulate p53 wild-type protein levels. 

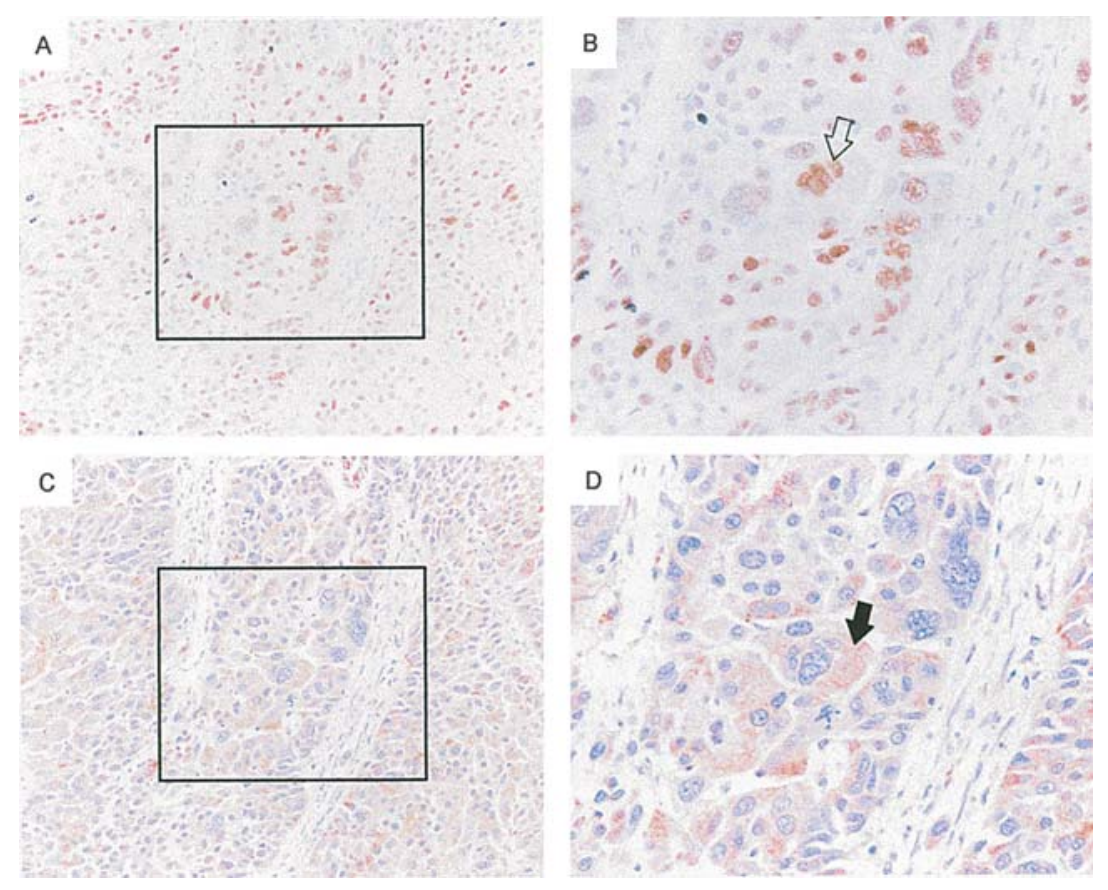

Figure 1. Granulin-epithelin precursor (GEP) and p53 protein staining in hepatocellular carcinoma. (A and B) p53 protein staining. Original magnification, x200 and x400, respectively. (C and D) GEP protein staining. Original magnification, x200 and x400, respectively. Protein signals were revealed as brown stain, and the sections were counterstained with hematoxylin.

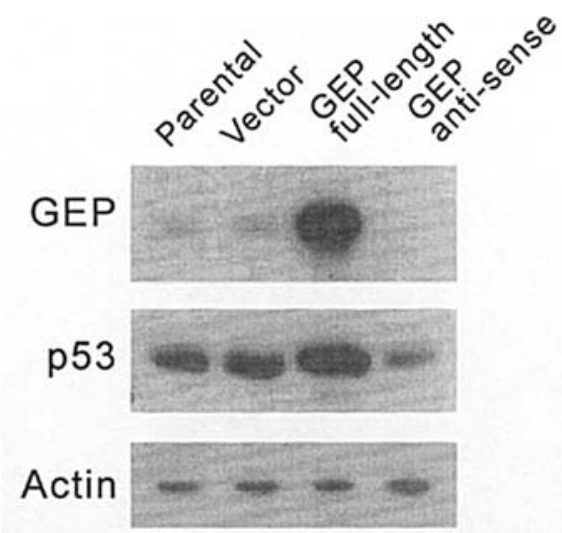

Figure 2. Effect of granulin-epithelin precursor (GEP) protein level changes on p53 protein levels in transfection experiments. In HepG2, with a p53 wild-type background, the alteration of GEP levels resulted in p53 level changes.

\section{Discussion}

Somatic mutations in the p53 tumor suppressor gene have been widely explored in HCCs from patients in different parts of the world (14-18). In regions with high dietary aflatoxin B1 and endemic with hepatitis B virus infection, typical $\mathrm{G}$ to $\mathrm{T}$ transversion at the third base in codon 249 is frequently observed. However, in Europe and our locality with a low level of dietary aflatoxin B1, p53 gene mutations are not common and only a few occur at codon 249 . The association of p53 gene mutation status with p53 protein accumulation has also been studied extensively. The present study, consistent with reports from the literature, also demonstrated that p53 mutations were frequently observed in HCCs with p53 protein accumulation. Our data also confirmed that p53 gene mutation might result in a biologically altered protein with increased stability, and was therefore detectable by immunohistochemistry as 553 protein nuclear accumulation $(19,20)$. Nevertheless, there were some HCCs with p53 mutation but no detectable p53 protein, revealing that the absence of p53 protein does not rule out the involvement of p53 gene aberration. Some of these exceptional cases revealed frameshift mutation (deletion in 3 cases and insertion in 2 cases), so the truncated protein might be unstable or the epitope masked and therefore undetectable by the monoclonal antibody DO-7 used in the experiment.

p53 protein accumulation is not always dependent on p53 gene mutation (21-25), and the mechanism involved is unclear. Although p53 protein accumulation can be a result of gene mutation and the $\mathrm{p} 53$ mutant protein is a more stable protein $(19,20)$, the current study demonstrates that p53 protein stabilization may be caused by events other than p53 gene mutation. Stabilization and inactivation of wild-type p53 protein by association with viral proteins, such as the hepatitis B virus X protein (27) and SV40 large T antigen (28), have been reported. As GEP protein is detectable in the cytoplasm and p53 protein is in the nucleus (Fig. 1), GEP protein is less likely to directly interact with $\mathrm{p} 53$ protein. Nonetheless, GEP could possibly enhance p53 transcription and/or translation through GEP downstream molecules, and thus result in an increased level of p53 protein. Alternatively, GEP could modulate the binding molecules of $\mathrm{p} 53$, and thereby stabilize the $\mathrm{p} 53$ protein. As wild-type p53 protein induces cell death by apoptosis (29), it would therefore be inactive for their accumulation in human tumors. Nevertheless, the exact mechanism of p53 and GEP regulation is unknown and warrants further investigation.

In our earlier study, GEP was frequently overexpressed in HCCs $(72 \%, 79 / 110)(11)$. Enhanced GEP expression in HCCs 
was associated with the more aggressive tumor features including large tumor, venous infiltration, and early intrahepatic recurrence. We also demonstrated by functional studies that GEP controlled the HCC cell proliferation rate, invasion and tumorigenicity. GEP protein is a secretory protein, and enhanced expression of GEP in the more aggressive cancers has also been reported in diverse cancer types (1-11). GEP has been reported to be involved in the wound healing process (12) and murine development (13). All of the data suggest that GEP is an important factor in the control of cell growth. However, GEP-associated genes and/or pathways are not well characterized. GEP activates a number of pathways in different cell types including p44/42 mitogen-activated protein kinase (MAPK) (30-32). The MAPK cascade can also be activated by p53 (33). Therefore, control of HCC growth and invasion by the MAPK pathway could be mediated by GEP through p53 up-regulation.

In summary, this is the first report on human cancers that reveal the association of GEP up-regulation with wild-type p53 protein nuclei accumulation. The current data were based on the study of HCC but encourage investigation into other human tumors for the involvement of GEP, especially tumor types that reveal nuclei accumulation of p53 wild-type protein. GEP is a novel growth factor that controls cell proliferation, invasion and tumorigenicity, while p53 wild-type protein accumulation is likely to be inactive. Nonetheless, the exact link between p53 and GEP is unknown, and the transcriptiondependent and -independent functions of wild-type p53 are also not well-known (34). Further study will be necessary to demonstrate the precise mechanism and functional implication of GEP overexpression and nuclei accumulation of wild-type p53 protein.

\section{Acknowledgements}

Supported in part by grants from the Sun C.Y. Research Foundation for Hepatobiliary and Pancreatic Surgery and Seed Funding Program of the University of Hong Kong, and the Hong Kong Research Grants Council (HKU 7392/03M).

\section{References}

1. Jones MB, Michener CM, Blanchette JO, Kuznetsov VA, Raffeld M, Serrero G, Emmert-Buck MR, Petricoin EF, Krizman DB, Liotta LA and Kohn EC: The granulin-epithelin precursor/PC-cell-derived growth factor is a growth factor for epithelial ovarian cancer. Clin Cancer Res 9: 44-51, 2003.

2. Davidson B, Alejandro E, Florenes VA, Goderstad JM, Risberg B, Kristensen GB, Trope CG and Kohn EC: Granulin-epithelin precursor is a novel prognostic marker in epithelial ovarian carcinoma. Cancer 100: 2139-2147, 2004.

3. He Z and Bateman A: Progranulin gene expression regulates epithelial cell growth and promotes tumor growth in vivo. Cancer Res 59: 3222-3229, 1999.

4. He Z, Ismail A, Kriazhev L, Sadvakassova G and Bateman A: Progranulin (PC-cell-derived growth factor/acrogranin) regulates invasion and cell survival. Cancer Res 62: 5590-5596, 2002.

5. Serrero G and Ioffe OB: Expression of PC-cell-derived growth factor in benign and malignant human breast epithelium. Hum Pathol 34: 1148-1154, 2003.

6. Lu R and Serrero G: Inhibition of PC cell-derived growth factor (PCDGF, epithelin/granulin precursor) expression by antisense PCDGF cDNA transfection inhibits tumorigenicity of the human breast carcinoma cell line MDA-MB-468. Proc Natl Acad Sci USA 97: 3993-3998, 2000.
7. Lu R and Serrero G: Mediation of estrogen mitogenic effect in human breast cancer MCF-7 cells by PC-cell-derived growth factor (PCDGF/granulin precursor). Proc Natl Acad Sci USA 98: 142-147, 2001.

8. Donald CD, Laddu A, Chandham P, Lim SD, Cohen C, Amin M, Gerton GL, Marshall FF and Petros JA: Expression of progranulin and the epithelin/granulin precursor acrogranin correlates with neoplastic state in renal epithelium. Anticancer Res 21: 3739-3742, 2001.

9. Wang W, Hayashi J, Kim WE and Serrero G: PC cell-derived growth factor (granulin precursor) expression and action in human multiple myeloma. Clin Cancer Res 9: 2221-2228, 2003.

10. Pan CX, Kinch MS, Kiener PA, Langermann S, Serrero G, Sun L, Corvera J, Sweeney CJ, Li L, Zhang S, Baldridge LA, Jones TD, Koch MO, Ulbright TM, Eble JN and Cheng L: PC cell-derived growth factor expression in prostatic intraepithelial neoplasia and prostatic adenocarcinoma. Clin Cancer Res 10: 1333-1337, 2004.

11. Cheung ST, Wong SY, Leung KL, Chen X, So S, Ng IO and Fan ST: Granulin-epithelin precursor overexpression promotes growth and invasion of hepatocellular carcinoma. Clin Cancer Res 10: 7629-7636, 2004.

12. He Z, Ong $\mathrm{CH}$, Halper $\mathrm{J}$ and Bateman A: Progranulin is a mediator of the wound response. Nat Med 9: 225-229, 2003.

13. Daniel R, Daniels E, He Z and Bateman A: Progranulin (acrogranin/PC cell-derived growth factor/granulin-epithelin precursor) is expressed in the placenta, epidermis, microvasculature, and brain during murine development. Dev Dyn 227: 593-599, 2003.

14. Hofseth LJ, Hussain SP and Harris CC: p53: 25 years after its discovery. Trends Pharmacol Sci 25: 177-181, 2004.

15. Staib F, Hussain SP, Hofseth LJ, Wang XW and Harris CC: TP53 and liver carcinogenesis. Hum Mutat 21: 201-216, 2003.

16. Wang XW, Hussain SP, Huo TI, Wu CG, Forgues M, Hofseth LJ, Brechot $\mathrm{C}$ and Harris CC: Molecular pathogenesis of human hepatocellular carcinoma. Toxicology 181-182: 43-47, 2002.

17. Hollstein M, Sidransky D, Vogelstein B and Harris CC: p53 mutations in human cancers. Science 253: 49-53, 1991

18. Levine AJ, Momand J and Finlay CA: The p53 tumour suppressor gene. Nature 351: 453-456, 1991.

19. Finlay CA, Hinds PW, Tan TH, Eliyahu D, Oren M and Levine AJ: Activating mutations for transformation by p53 produce a gene product that forms an hsc70-p53 complex with an altered half-life. Mol Cell Biol 8: 531-539, 1988.

20. Kraiss S, Spiess S, Reihsaus E and Montenarh M: Correlation of metabolic stability and altered quaternary structure of oncoprotein p53 with cell transformation. Exp Cell Res 192: 157-164, 1991.

21. Bourdon JC, D'Errico A, Paterlini P, Grigioni W, May E and Debuire B: p53 protein accumulation in European hepatocellular carcinoma is not always dependent on p53 gene mutation. Gastroenterology 108: 1176-1182, 1995.

22. Cesarman E, Inghirami G, Chadburn A and Knowles DM: High levels of p53 protein expression do not correlate with p53 gene mutations in anaplastic large cell lymphoma. Am J Pathol 143: 845-856, 1993.

23. Villuendas R, Piris MA, Algara P, Sanchez-Beato M, Sanchez-Verde L, Martinez JC, Orradre JL, Garcia P, Lopez C and Martinez P: The expression of p53 protein in non-Hodgkin's lymphomas is not always dependent on p53 gene mutations. Blood 82: 3151-3156, 1993.

24. Rubio MP, von Deimling A, Yandell DW, Wiestler OD, Gusella JF and Louis DN: Accumulation of wild type p53 protein in human astrocytomas. Cancer Res 53: 3465-3467, 1993.

25. Lang FF, Miller DC, Pisharody S, Koslow M and Newcomb EW: High frequency of p53 protein accumulation without p53 gene mutation in human juvenile pilocytic, low grade and anaplastic astrocytomas. Oncogene 9: 949-954, 1994.

26. Lehman TA, Bennett WP, Metcalf RA, Welsh JA, Ecker J, Modali RV, Ullrich S, Romano JW, Appella E, Testa JR, et al: p53 mutations, ras mutations, and p53-heat shock 70 protein complexes in human lung carcinoma cell lines. Cancer Res 51: 4090-4096, 1991.

27. Feitelson MA and Duan LX: Hepatitis B virus $X$ antigen in the pathogenesis of chronic infections and the development of hepatocellular carcinoma. Am J Pathol 150: 1141-1157, 1997.

28. Ludlow JW: Interactions between SV40 large-tumor antigen and the growth suppressor proteins pRB and p53. FASEB J 7: 866-871, 1993. 
29. Yonish-Rouach E, Resnitzky D, Lotem J, Sachs L, Kimchi A and Oren M: Wild-type p53 induces apoptosis of myeloid leukaemic cells that is inhibited by interleukin-6. Nature 352: 345-347, 1991.

30. Serrero G: Autocrine growth factor revisited: PC-cell-derived growth factor (progranulin), a critical player in breast cancer tumorigenesis. Biochem Biophys Res Commun 308: 409-413, 2003.

31. Ong $\mathrm{CH}$ and Bateman A: Progranulin (Granulin-epithelin precursor, PC-cell derived growth factor, Acrogranin) in proliferation and tumorigenesis. Histol Histopathol 18: 1275-1288, 2003.
32. He Z and Bateman A: Progranulin (granulin-epithelin precursor, PC-cell-derived growth factor, acrogranin) mediates tissue repair and tumorigenesis. J Mol Med 81: 600-612, 2003.

33. Fang L, Li G, Liu G, Lee SW and Aaronson SA: p53 induction of heparin-binding EGF-like growth factor counteracts p53 growth suppression through activation of MAPK and PI3K/Akt signaling cascades. EMBO J 20: 1931-1939, 2001.

34. Sengupta S and Harris CC: p53: traffic cop at the crossroads of DNA repair and recombination. Nat Rev Mol Cell Biol 6: 44-55, 2005. 